\title{
Burnout and Coping Strategies among Private Fitness Centre Employees
}

\author{
Yannis S. Georgiou' ${ }^{1}$, Aggeliki Fotiou ${ }^{2}$ \\ Affiliations: 'National \& Kapodistrian University of Athens, School of Physical Education and Sport Science, Athens, \\ Greece, ${ }^{2}$ Hellenic Open University, Faculty of Business Administration, Patras, Greece
}

Correspondence:Y.S. Georgiou, 33 Terpsichoris St., Agios Dimitrios, 17341, Athens, Greece, email: georgiougiannis72@ gmail.com

ABSTRACT This study aimed to examine the relationships between burnout and coping strategies among private health and fitness centre employees. Using a stratified random sampling method, a sample of 205 employees (50.7\% males and $49.3 \%$ females) (51.2\% full time and $48.8 \%$ part-time) completed the Maslach Burnout Inventory-General Survey (MBI-GS) and Ways of Coping Survey questionnaires. Statistical analysis showed that passive coping was associated with higher levels of depersonalization and lack of personal accomplishment while active coping has a possible negative effect on the development of burnout.

KEY WORDS emotional exhaustion, cynicism, personal accomplishment, coping

$@ M J S S M o n t e n e g r o$

BURNOUT AND COPING STRATEGIES

http://mjssm.me/?sekcija=article\&artid=180

\section{Introduction}

In psychology, when referring to a syndrome, a set of clues and symptoms that characterize a particular malfunction is meant (Shirom, 2005). Occupational Exhaustion Syndrome or Burnout Syndrome (BS) consists of three dimensions: emotional exhaustion, depersonalization or cynicism, and reduced personal accomplishment (Maslach, Schaufeli, \& Leiter, 2001). In the past, it was considered to be primarily associated with social service professionals (Grunfeld et al., 2000). However, as the research interest went on to other occupational sectors, results showed that other occupational groups could also be affected (Maslach \& Schaufeli, 1993). The cost of tackling BS is substantial, both for employees and employers or even for national economies. Indicatively, as a result of BS, the cost for the US economy is about $\$ 300$ billion per year due to sick leave absenteeism, long-term or permanent disability requiring compensation, and staff retirement as a result of work-related resignation; in the UK, lost labour hours and reduced productivity due to workers' dissatisfaction with work cost the economy 46 billion British pounds (Leiter \& Maslach, 2007). Survey results in many developed countries show high rates of BS occurrence, in proportion to their workforce. Thus, $4-7 \%$ of the workforce in the Netherlands shows symptoms of advanced BS, 7.4\% in Sweden, a similar rate in Finland and slightly higher in Denmark (up to 10\%) (Kristensen, Borritz, Villadsen, \& Christensen, 2005; Schaufeli \& Enzmann, 1998).

The ways in which an employee can avoid developing BS are found in the coping strategies for addressing stressful stimuli. This theory is based on the studies of Lazarus and Folkman (1984) and Lazarus (1991); both agree that there are two ways of coping with stressful stimuli. The first one is adopting a passive attitude, without any reaction. It is the so-called emotional way in which a person attempts, with various techniques such as avoidance, escape, or wishful thinking, to alleviate the negative effect of the stressful stimuli and the negative emotions evolved. The individual tries to feel transiently better, without making an effort to deal with, to manage, or to resolve the stressful situation. Such a situation, however, perpetuates the stress conditions and leads to the development of BS.

The second way refers to active and dynamic strategies for addressing stressful stimuli. By applying a similar strategy, the individual acts systematically to deal with it and to solve it as promptly as possible. In such situations, the person collects information about the situation she/he has to manage, organizes and systemizes it, plans an action with its alternatives, implements it, and attempts in every possible way to attain its solution.

Received: December 062018 | Accepted after revision: March 212019 | First published online: September 012019

(C) 2019 by the author(s). License MSA, Podgorica, Montenegro. This article is an open access article distributed under the terms and conditions of the Creative Commons Attribution (CC BY).

Conflict of interest: None declared. 
This way of acting reduces the chances of developing BS, exhaustion and cynicism, while also enhancing the self-efficacy and the sense of occupational satisfaction of the individual.

In general, problem-oriented active coping strategies are more effective in dealing with stressful emotions than emotional, passive-oriented coping strategies are. This is because emotionally oriented strategies include tactics, such as taking distance from a stressful situation, avoiding it, and seeking external support, with the ultimate goal of simply reducing the emotional impact of the stressful stimuli. In contrast, strategies that focus on the problem include collecting information about the problem, preparing a response plan, finding alternatives, and adhering to the action plan. Several research studies' results showed that the problem-oriented strategy seems to have a protective effect against BS due to its de-stressing character and a positive effect on personal occupational achievements and the sense of high professional ability, while passive coping strategies made a substantial contribution to the emergence of burnout and cynicism while presenting a positive correlation of exhaustion on depersonalization (Wiese, Rothmann, \& Storm, 2003).

If chronic exposure to stress is the result of a person's choice of passive strategies to deal with stressful situations while choosing active strategies reduces the risk of developing BS, then there may be a solution for avoiding the occurrence of BS: the proper training for employees to choose the correct strategies for dealing with stressful situations.

Among other occupational areas, researchers' interest turned to sport. Research has examined physical education teachers, coaches, or even athletes and business executives (Caccese \& Mayerberg, 1984; Kelley, Eklund, Ritter, \& Taylor, 1999; Koustelios \& Tsigilis, 2005; Koustelios, 2001; Kubayi, 2018; Martin, Kelley, \& Dias, 1999; Tsigilis, Zournatzi, \& Koustelios, 2011).

Nevertheless, to date, there is no known literature concerning the existence of burnout among private sport and fitness centres sector employees and their coping strategies. The present study seeks to explore the connection between $\mathrm{BS}$ and the coping strategies used in the context of the private sports sector services.

\section{Methods}

\section{Participants}

Participants were 205 employees of private fitness centres from the region of Attica, Greece, 104 (50.7\%) men and 101 (49.3\%) women, of whom 105 (51.2\%) were working full time and 100 (48.8\%) part-time. With regard to the age of the participants, $82.9 \%$ ( 81 men and 89 women) belong to the 18 -37 age group, and $17.1 \%$ (23 men and 12 women) are aged 38 to 67 years.

\section{Measures}

Maslach Burnout Inventory-General Survey (MBI-GS)

For the purpose of the present study, the Maslach Burnout Inventory-General Survey (MBI - GS) (Maslach,

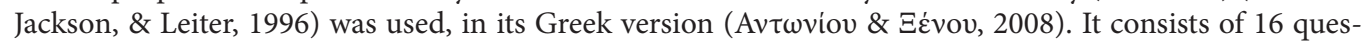
tions, five of which refer to emotional exhaustion, six questions refer to depersonalization, while the last five refer to personal achievements. Respondents expressed their opinion on a seven-point Likert scale, in which " $1=$ never" and " $7=$ every day". The credibility of internal consistency was found to be satisfactory for Emotional Exhaustion $\alpha=0.83$, Depersonalization $\alpha=0.71$, and Personal Accomplishments $\alpha=0.81$.

\section{Coping Strategies Questionnaire}

The Coping Strategies Questionnaire consists of 25 sentences. It is designed to measure both positive and negative strategies used by an individual to overcome different stressful situations. Respondents are asked to evaluate the 25 stress-response strategies using a four-dimensional Likert type scale (from " $1=$ I have not used it" to " $4=$ I have used it very often"). Stress management strategies are divided into the following subclasses and are similar to those proposed by Lazarus and Folkman (1984).

The Positive Approach includes eight questions that evaluate the person's attempt to re-evaluate stressful situations in a positive way and to design techniques to solve the problem ("I concentrated on what I had to do next", "I was trying to see the optimistic side of things", "I was altering something to make a positive turn", "I stood on my feet, and I fought for what I wanted", "I used past experiences", "I was doubling my efforts", "I got alternatives to a problem", "I made a plan of action and I implemented"). The reliability Cronbach index was a $=0.74$.

Assertive Problem Solving, with 5 questions, evaluates the individual's attempt to achieve a solution by confidently addressing the situation or the person who creates it ("I was trying to address the responsible person to change my mind", "I was out the anger in the person responsible for the problem", "I did something risky to change the problem", "I rushed to other people", "I did something I did not think would work, but at least I did something"). The reliability Cronbach index was $\alpha=0.60$.

Avoidance/Escape includes eight questions and is related to avoiding the stressful stimuli, reducing or ignoring their true meaning ("I continued as if nothing had happened", "I was trying to forget the whole thing", "I kept my feelings away", "I was trying to feel better by eating or taking medication", "I avoided being with people", "I refused to think about it", "I did not mind the situation", "I refused to think about what had happened"). The reliability Cronbach index was $\alpha=0.64$. 
Wishful Thinking includes four questions and evaluates the person's tendency to overcome the problems by wishing a miracle ("I was hoping for a miracle", "I accepted the fate, sometimes I have bad luck", "I wished the situation to end in some way", "I thought things could evolve"). The reliability Cronbach index was $\alpha=0.60$.

A demographic variables questionnaire concerning gender, age, type of employment, work status, and other factors was also distributed.

\section{Data collection and analysis}

Participants were chosen following a combination of stage and random sampling methods; with reference to four out of the eight administrative districts of the Attica Region, 25 out of the 35 municipalities in the four administrative districts, 101 out of 201 private gyms in preselected municipalities were initially identified. The questionnaires with delivered and collected within 15 days. The questionnaire package also included a cover letter informing prospective participants of the purposes of the survey, the optional and voluntarily nature of their participation, and the anonymity of their responses. The statistical analysis was completed using the SPSS 19 statistical package for social sciences (SPSS Inc., Chicago IL, USA) and included descriptive statistics with means (M.) and standard deviations (S.D.), simple regression analysis ANOVA, and stepwise multiple regressions using the enter method.

\section{Results}

According to the results of the analysis of variance of the Coping Strategies Questionnaire, males are more assertive than females are in coping with stressful situations, whereas females resort more than males in Wishing $\mathrm{F}(1,204)=3.20, \mathrm{p}=0.05$. No differences were found related to the participants' working status (see Table 1).

\begin{tabular}{|c|c|c|c|c|}
\hline \multirow{2}{*}{ Coping Strategies } & \multicolumn{4}{|c|}{ Gender } \\
\hline & Males & Females & Total & $\mathbf{F}$ \\
\hline & M. & M. & M. & \\
\hline Positive Approach & 1.94 & 1.98 & 1.96 & 0.28 \\
\hline Assertive Problem Solving & 0.89 & 1.03 & 0.96 & $3.32 *$ \\
\hline Avoidance / escape & 1.11 & 1.05 & 1.08 & 0.73 \\
\hline Wishful Thinking & 1.28 & 1.11 & 1.20 & $4.59 *$ \\
\hline
\end{tabular}

Note. ${ }^{*} p<0.05 .{ }^{* *} p<0.01 .{ }^{* * *} p<0.001$.

In order to examine the statistical prediction of the coping strategies for addressing stressful situations (dependent variables) of the participants from the factors of the MBI-GS Questionnaire (independent variables), four hierarchical regressions were performed using the enter method.

In the first step, gender was introduced, in the second working status, and in the third one the BS factors (emotional exhaustion, depersonalization and personal accomplishment). Table 2 presents the prediction of the Positive Approach from BS subscales. The results show that Personal Accomplishment positively predicts the Positive Approach, $\beta=0.18, \mathrm{t}=2.43, \mathrm{p}<0.05 \mathrm{R}^{2}=3.4 \%$.

\begin{tabular}{|c|c|c|c|c|}
\hline \multirow{2}{*}{ Predictors } & \multicolumn{4}{|c|}{ Possitive Approach } \\
\hline & $\beta$ & $\mathbf{t}$ & $\mathbf{R}^{2}$ & $\mathbf{F}$ \\
\hline Gender & 0.04 & 0.54 & 0.001 & 0.28 \\
\hline Work Status & -0.05 & -0.71 & 0.005 & 1.1 \\
\hline \multicolumn{5}{|l|}{ Burnout } \\
\hline Emotional exhaustion & -0.01 & -0.16 & 0.034 & 2.38 \\
\hline Depersonalization & -0.05 & -0.60 & & \\
\hline Personal accomplishment & 0.18 & $2.43 *$ & & \\
\hline
\end{tabular}

Note. ${ }^{*} \mathrm{p}<0.05 .{ }^{* *} \mathrm{p}<0.01 .{ }^{* * *} \mathrm{p}<0.001$.

Table 3 presents the prediction of Assertive Problem Solving from the MBI-GS questionnaire factors. The results show that males are more assertive for a problem's solution than females are, $\beta=0.13, t=2.02, p$ $<0.05 \mathrm{R}^{2}=1.6 \%$. Emotional Exhaustion $\beta=0.22, \mathrm{t}=3.23, \mathrm{p}<.0$ and Depersonalization $\beta=.21, \mathrm{t}=3.14$, $\mathrm{p}<0.01$ contribute positively to the Assertive Problem Solving, while the contribution of Personal Accomplishment is negative $\beta=-0.21, \mathrm{t}=-3.20, \mathrm{p}<0.01$. The overall contribution of the prediction of the Assertive Problem Solving strategy from the MBI-GS questionnaire is $\mathrm{R}^{2}=17 \%$. 
TABLE 3 Regression analysis of the Assertive Problem Solving from gender, work status and MBI-GS questionnaire factors

\begin{tabular}{lcccc} 
& \multicolumn{4}{c}{ Assertive Problem Solving } \\
\cline { 2 - 5 } Predictors & $\boldsymbol{\beta}$ & $\mathbf{t}$ & $\mathbf{R}^{\mathbf{2}}$ & $\mathbf{F}$ \\
\hline Gender & $13.00^{*}$ & 2.02 & 0.016 & 3.32 \\
Work Status & 0.05 & 0.79 & 0.009 & 1.85 \\
Burnout & & & 0.17 & $13.95^{* * *}$ \\
Emotional exhaustion & $0.22^{* *}$ & 3.23 & \\
Depersonalization & $0.21^{* *}$ & 3.14 & \\
Personal accomplishment & $-0.21^{* *}$ & -3.20 & & \\
\hline
\end{tabular}

Note. ${ }^{*} \mathrm{p}<0.05 .{ }^{* *} \mathrm{p}<0.01 .{ }^{* * *} \mathrm{p}<0.001$.

The prediction of Avoidance / Escape coping strategy is shown in Table 4. Depersonalization $\beta=0.18, t=2.55$, $\mathrm{p}<0.01$ contributes positively to the Avoidance/Escape coping strategy, while the contribution of Personal Accomplishment is negative $\beta=-0.16, t=2.29, p<0.01$. The overall contribution of the prediction of this coping strategy from the MBI-GS questionnaire is $\mathrm{R}^{2}=9 \%$.

\begin{tabular}{lcccc} 
TABLE 4 Regression analysis of Avoidance/Escape strategy from gender, work status and MBI-GS \\
questionnaire factors \\
\cline { 2 - 5 } Predictors & $\boldsymbol{\beta}$ & $\mathbf{t}$ & $\mathbf{R}^{\mathbf{2}}$ & $\mathbf{F}$ \\
\hline Gender & -0.05 & -0.78 & 0.004 & 0.73 \\
Work Status & 0.09 & 1.27 & 0.014 & 2.83 \\
Burnout & & & 0.09 & $6.88^{* * *}$ \\
Emotional exhaustion & 0.13 & 1.77 & & \\
Depersonalization & $0.18^{* *}$ & 2.55 & & \\
Personal accomplishment & $-0.16^{* *}$ & -2.29 & &
\end{tabular}

Note. ${ }^{*} p<0.05 .{ }^{* *} p<0.01 .{ }^{* * *} p<0.001$.

Concerning the prediction of the Wishful Thinking strategy from the MBI-GS factors, results are presented in Table 5. Females are associated with a higher level of using the Wishful Thinking strategy to manage a stressful situation $\beta=-0.14, t=-2.03, p<0.05, R^{2}=2.2 \%$. Emotional Exhaustion $\beta=0.20, t=2.84, p<0.01$ and depersonalization $\beta=0.14, \mathrm{t}=1.91, \mathrm{p}<0.05$ contribute positively to the use of Wishful Thinking as a stress management strategy, while the contribution of personal accomplishments is negative $\beta=-0.13$, $\mathrm{t}=-1.93, \mathrm{p}<0.05$. The overall contribution of predicting the use of Wishful Thinking from the MBI-GS questionnaire factor is $\mathrm{R}^{2}=9 \%$.

\begin{tabular}{|c|c|c|c|c|}
\hline \multirow{2}{*}{ Predictors } & \multicolumn{4}{|c|}{ Wishing } \\
\hline & $\boldsymbol{\beta}$ & $\mathbf{t}$ & $\mathbf{R}^{2}$ & $\mathbf{F}$ \\
\hline Gender & $-0.14 *$ & -2.03 & 0.022 & $4.59 *$ \\
\hline Work Status & 0.10 & 1.53 & 0.018 & $3.76^{*}$ \\
\hline Burnout & & & 0.09 & $6.98 * * *$ \\
\hline Emotional exhaustion & $0.20 * *$ & 2.84 & & \\
\hline Depersonalization & $0.14 *$ & 1.91 & & \\
\hline Personal accomplishment & $-0.13 *$ & -1.93 & & \\
\hline
\end{tabular}

Note. ${ }^{*} p<0.05$. ${ }^{* *} p<0.01$. ${ }^{* * *} p<0.001$.

\section{Discussion}

The aim of the present study was twofold. Initially, the choices of coping strategies towards stressful situations were examined, with references to the factors of gender and work status in the private fitness centre employees. The results showed that male employees make statistically significant higher use of Assertive Problem-Solving strategy than their female counterparts do. In contrast, female employees make statistically significant use of the Wishful Thinking strategy at higher levels than their male colleagues do. There was no statistical significance found between genders concerning the Positive Approach or the Avoidance/ Escape coping strategies' use.

The second aim of the study was to examine the prediction of coping strategies from the Burnout factors through the MBI-GS questionnaire. The results showed that Personal Accomplishments predicts the Positive Approach strategy up to 3.4\%. Burnout variables in total explain 17\% of the Assertive Problem Solving strategy. In more detail, Emotional Exhaustion and Depersonalization contribute positively while Personal Accomplishments contribute negatively. Concerning the coping strategy of Avoidance/Escape, 
both Depersonalization and Personal Accomplishments contribute positively with an overall explanation of up to 9\%. Finally, Emotional Exhaustion and Depersonalization contribute positively, while Personal Accomplishment contributes negatively to the Wishful Thinking strategy with a total of $9 \%$ of explanation BS factors.

The results point towards two directions. The first direction concerns the gender factor. Female employees make use of passive coping strategies while male employees use more active ones. The second direction shows that passive strategies are closely connected and can be predicted by BS factors and they are positively connected with Emotional Exhaustion and Depersonalization, while active coping strategies are positively connected and predicted by Personal Accomplishment. Interpreting the abovementioned point, an employee using passive strategies cannot manage stressful situations successfully and may already have or is about to develop BS. That means that female employees may be at greater risk, and they need more help than their male counterparts do. In contrast, an employee with high levels of Personal Accomplishments regularly uses active strategies, which means that he/she can respond successfully to a stressful situation while maintaining low stress levels.

In conclusion, this study gives a first class opportunity to the management of the private sport sector by using the coping strategies choices' of their employees as an indicator, as a diagnostic tool, and as a deterrence tool. Management should be able to recognize the signs of their employees' coping strategies choices and should be able to train and guide them to use active coping strategies to manage stressful situations more efficiently. Proper active coping strategies on behalf of the employees will reduce the stress effects of stressful situations and will work as a precaution measure towards the appearance of Burnout Syndrome. Future research should also have more extensive samples, from different employee groups of the sport service sector, even in a longitudinal perspective for more reliable and generalized results.

\section{REFERENCES}

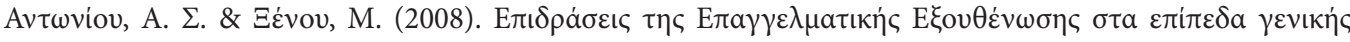

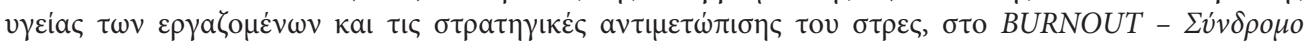

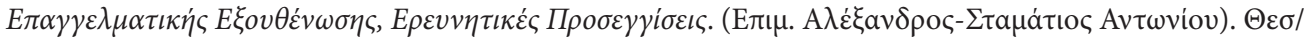
víkๆ: University Studio Press [in Greek].

Caccese, T., \& Mayerberg, C. (1984). Gender differences in perceived burnout of college coaches. Journal of Sport Psychology, 6, 279-288, doi: 10.1123/jsp.6.3.279

Grunfeld, E., Whelan, T., Zitzelsberger, L., Willan, A., Montesanto, B., \& Evans, W. (2000). Cancer care workers in Ontario: Prevalence of burnout, job stress and job satisfaction. Canadian Medical Association Journal, $163,166-169$.

Kelley, B., Eklund, R., Ritter, C., \& Taylor, M. (1999). Stress and burnout among collegiate tennis coaches. Journal of Sport and Exercise Psychology, 21, 113-130, doi: 10.1123/jsep.21.2.113

Koustelios, A. (2001). Burnout among Greek sport centres employees. Sport Management Review, 4(2), 151163, doi: 10.1016/S1441-3523(01)70073-3

Koustelios, A. \& Tsigilis, N. (2005). Relationship between burnout and job satisfaction among physical education teachers: A multivariate approach. European Physical Education Review, 11(2), 189-203, doi: $10.1177 / 1356336$ X05052896

Kristensen, T. S., Borritz, M., Villadsen, E., \& Christensen, K. B. (2005a). The Copenhagen Burnout Inventory: A new tool for the assessment of burnout. Work \& Stress, 19(3), 192-207, doi: 10.1080/02678370500297720

Kubayi, A. (2018). Burnout and paths to turnover intentions among South African Sport Coaches. Montenegrin Journal of Sports Science and Medicine, 7(2), 43-47, doi: 10.26773/mjssm.180907

Lazarus, R. S. \& Folkman, S. (1984). Stress appraisal and coping. New York: Springer.

Lazarus, R. S. (1991). Psychological stress in the workplace. Journal of Social Behavior and Personality, 6, 1-13.

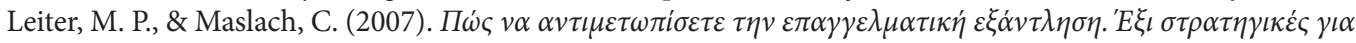

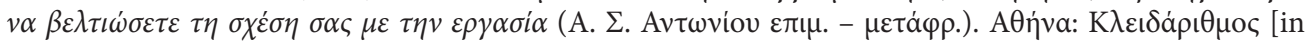
Greek].

Martin, J., Kelley, B., \& Dias, C. (1999). Stress and burnout in female high school athletic directors. Women in Sport and Physical Activity Journal, 8, 101-116, doi: 10.1123/wspaj.8.1.101

Maslach, C., Jackson, S. E., \& Leiter, M. P. (1996). Maslach Burnout Inventory Manual 3rd ed. Palo Alto, CA: Consulting Psychologists Press.

Maslach, C., \& Jackson, S. E. (1981). The measurement of experienced burnout. Journal of Occupational Behavior, 2, 99-115, doi: 0142-2774/81/020099-15

Maslach, C., \& Schaufeli, W. (1993). Historical and conceptual development of burnout. In W. Schaufeli, C. Maslach, \& T. Marek (Eds.), Professional burnout: Recent developments in theory and research (pp. 1-16). London: Taylor \& Francis, doi: 10.4324/9781315227979

Maslach, C., Schaufeli, W. B. \& Leiter, M. P. (2001). Job burnout. Annual Review of Psychology, 52, 397- 422, doi: 0066-4308/01/0201-0397

Schaufeli, W. B. \& Enzmann, D. (1998). The burnout companion to study and practice: A critical analysis. Philadelphia: Taylor \& Francis Ltd.

Shirom, A. (2005). Reflections on the study of burnout. Work \& Stress, 19(3), 263 - 270, doi: $10.1080 / 02678370500376649$ 
Tsigilis, N., Zournatzi, E., \& Koustelios, A. (2011). Burnout among Physical Education Teachers in Primary and Secondary Schools. International Journal of Humanities and Social Science, 7(1), 53-58, doi: 10.30845/ ijhss

Wiese, L., Rothmann, S., \& Storm, K. (2003). Coping, Stress and Burnout in The South African Police Service in Kwazulu-Natal. S.A. Journal of Industrial Psychology, 29(4), 71-80, ISSN 0258-5200 